Open Access

\title{
Incidentalomas during imaging for primary hyperparathyroidism-incidence and clinical outcomes
}

\author{
P. Prasad ${ }^{1,3^{*}}$, C. Clout $^{2}$, E. Lorenz ${ }^{2}$, B. J. Harrison ${ }^{1}$ and S. P. Balasubramanian ${ }^{1,3}$
}

\begin{abstract}
Background: Imaging for pre-operative localisation of parathyroid glands in primary hyperparathyroidism is now routine. This has led to the detection of incidental lesions (incidentalomas) in other organs, the nature of which is not well characterised.

The aim of this study was to determine the incidence, characteristics and outcomes in patients who had incidental findings on parathyroid imaging.

Methods: Records of patients who underwent imaging for primary hyperparathyroidism over 2 years were reviewed to identify incidental lesions detected on parathyroid imaging. Patients with persistent or renal hyperparathyroidism were excluded. Details on the management of detected incidentalomas were obtained from patient records.

Results: Incidentalomas were identified in 17 of 170 patients $(10 \%)$ undergoing parathyroid imaging. Incidentalomas included thyroid $(n=11)$, breast $(n=3)$, lateral compartment of the neck $(n=1)$, lung $(n=1)$ and clavicle $(n=1)$. However, no disease of clinical significance needing treatment was detected on further investigation.

Conclusions: Although a significant proportion of patients undergoing parathyroid imaging had incidental lesions detected, these seem to be of little clinical significance. The morbidity and cost of further interventions on these incidentalomas need to be weighed against the benefits of routine imaging in improving outcomes of first-time surgery in patients with primary hyperparathyroidism.
\end{abstract}

Keywords: Parathyroid gland, Primary hyperparathyroidism, Imaging, Incidentalomas

\section{Background}

Primary hyperparathyroidism (pHPT) is a common cause of hypercalcaemia and the third most frequently diagnosed endocrine disorder [1-3]. It occurs as a result of one or more overactive parathyroid glands; single-gland disease accounts for the majority of cases [2-5]. Whilst bilateral neck exploration used to be the mainstay of surgical treatment, minimally invasive surgical options are increasingly adopted [3-7]. Minimally invasive surgery relies on accurate pre-operative localisation of the abnormal gland(s). Technetium ${ }^{99}$ sestamibi (Tc99m MIBI) and

\footnotetext{
* Correspondence: Pooja.Prasad@doctors.org.uk

'Endocrine Surgery Unit, Department of General Surgery, Sheffield Teaching Hospitals NHS Foundation Trust, Sheffield, UK

${ }^{3}$ Academic Unit of Surgical Oncology, Department of Oncology, School of Medicine and Biomedical Sciences, The University of Sheffield, Sheffield S10 2RX, UK

Full list of author information is available at the end of the article
}

cervical ultrasound (USS) are the most widely used investigations for pre-operative parathyroid localisation.

The use of pre-operative imaging in $\mathrm{PHPT}$ has led to the increased detection of incidentally detected lesions or 'incidentalomas' in other organs. For example, ultrasound can detect co-existing thyroid nodules as the thyroid gland is routinely evaluated in parathyroid imaging $[5,8]$. Detection of these and other lesions elsewhere could lead to further investigations and surgery. The benefits of these interventions to the patient are debatable. Moreover, the results of imaging studies have the potential to delay parathyroid surgery and this may contribute to increased morbidity.

A series of such incidental lesions detected at this institution led to the initiation of this study. The aim of this study was to determine the incidence, management and clinical

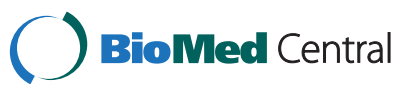

(C) 2015 Prasad et al. Open Access This article is distributed under the terms of the Creative Commons Attribution 4.0 International License (http://creativecommons.org/licenses/by/4.0/), which permits unrestricted use, distribution, and reproduction in any medium, provided you give appropriate credit to the original author(s) and the source, provide a link to the Creative Commons license, and indicate if changes were made. The Creative Commons Public Domain Dedication waiver (http://creativecommons.org/publicdomain/zero/1.0/) applies to the data made available in this article, unless otherwise stated. 
outcomes of incidentally detected lesions identified during pHPT imaging.

The objectives of the study were as follows:

1. Determine the incidence of incidentalomas during imaging for $\mathrm{pHPT}$ in a tertiary care institution over a 2-year period.

2. Identify the management strategies adopted and clinical outcomes following treatment of these incidentally detected lesions.

3. Evaluate any differences in length of waiting for parathyroidectomy amongst patients with and without incidentalomas.

\section{Methods}

This was a retrospective cohort study. All patients who had a Tc99m MIBI and/or USS performed for parathyroid localisation prior to first-time surgery for pHPT between January 2010 and December 2011 at Sheffield Teaching Hospitals NHS Foundation Trust were included in this study.

The reports of Tc99m MIBI and USS scans in patients with $\mathrm{pHPT}$ were reviewed by one author (PP). Patients undergoing parathyroid imaging for persistent $\mathrm{pHPT}$ or renal hyperparathyroidism and patients who had undergone imaging in other hospitals were excluded. Any uncertainties regarding eligibility for inclusion into the study were discussed with the lead author (SPB). Data on the identification and lateralisation of enlarged glands and on the presence and nature of any incidental lesions identified was collected from radiology reports. A new finding unrelated to parathyroid pathology was deemed to be an 'incidentaloma' based on the reporting radiologist's interpretation of the finding and on whether he/she had noted sufficient concern to warrant further investigation.

Further information on investigations performed for the incidentalomas, the results of these investigations, management strategies, relevant clinical outcomes and time taken from initial parathyroid imaging to surgery was retrieved from electronic and/or paper records. The Mann-Whitney $U$ test was utilised to determine if there was a statistically significant difference in waiting times between patients with and without incidentalomas.

The proposal for the study was approved by the trust's Clinical Effectiveness Unit.

\section{Results}

One hundred eighty-nine patients underwent parathyroid gland localisation scans between January 2010 and December 2011. Figure 1 demonstrates the process of inclusion of patients and the number and type of incidentalomas detected in this study.
The mean (standard deviation) age of the patients included in this study was 61(15.7) years. Most patients were females (114 or $67.1 \%$ of the study population).

Seventeen of the 170 patients $(10 \%)$ undergoing imaging for $\mathrm{pHPT}$ had incidental lesions identified. Twelve of these were identified on ultrasound, and five were detected by a Tc99m MIBI scan. There was no concordance between the imaging modalities for any incidental lesion identified.

Eleven patients had thyroid nodules incidentally detected by ultrasound, that radiologists suggested required further investigation or monitoring. Six of these patients underwent an USS-guided fine-needle aspiration (FNA) of the thyroid nodule. Cytology from the FNA was benign in five patients and indeterminate in one patient. The patient with the indeterminate result had a lobectomy, the histology of which was benign. A total of four patients had the thyroid gland examined macroscopically at parathyroidectomy and had nodules excised or a lobectomy performed. Table 1 summarises the histological findings from the excised thyroid tissue in the five patients (macroscopic thyroid gland examination $n=4$; lobectomy for indeterminate thyroid nodule $n=1$ ) who underwent surgery. One patient had a $1.5-\mathrm{mm}$ papillary microcancer detected histologically in a specimen that was predominantly a colloid goitre. One patient with a thyroid incidentaloma was managed conservatively; a follow-up ultrasound did not demonstrate any change to the incidental thyroid lesion.

Of the three patients with incidental breast lesions on MIBI scan, one patient had a breast ultrasound, one patient had a mammogram and one patient underwent both forms of imaging. No malignant features were identified in any patient, and none were subjected to biopsy.

Three patients had lesions detected elsewhere in the body. One patient had an enlarged cervical lymph node identified on ultrasound. Cytology from ultrasoundguided aspiration showed low-grade lymphoproliferative disease. As the patient was already under the care of haematologists for indolent non-Hodgkin's lymphoma at the time of the scan, no further action was taken. The second patient had a lesion identified in the right lung on MIBI scan. CT thorax/abdomen and a PET scan confirmed an indeterminate lung nodule, thought to be a neuroendocrine tumour. The patient is being monitored by annual imaging. The third patient had increased uptake in the left clavicle on MIBI and underwent an $\mathrm{X}$-ray. This demonstrated a normal bony appearance, and no further investigation or treatment was performed.

The median (interquartile range) waiting time for parathyroid surgery for patients with and without incidentalomas was $6.4(3.5-7.0)$ and 5 (3.1-7.3) months, respectively; this was not statistically significant $(p=0.398)$. 


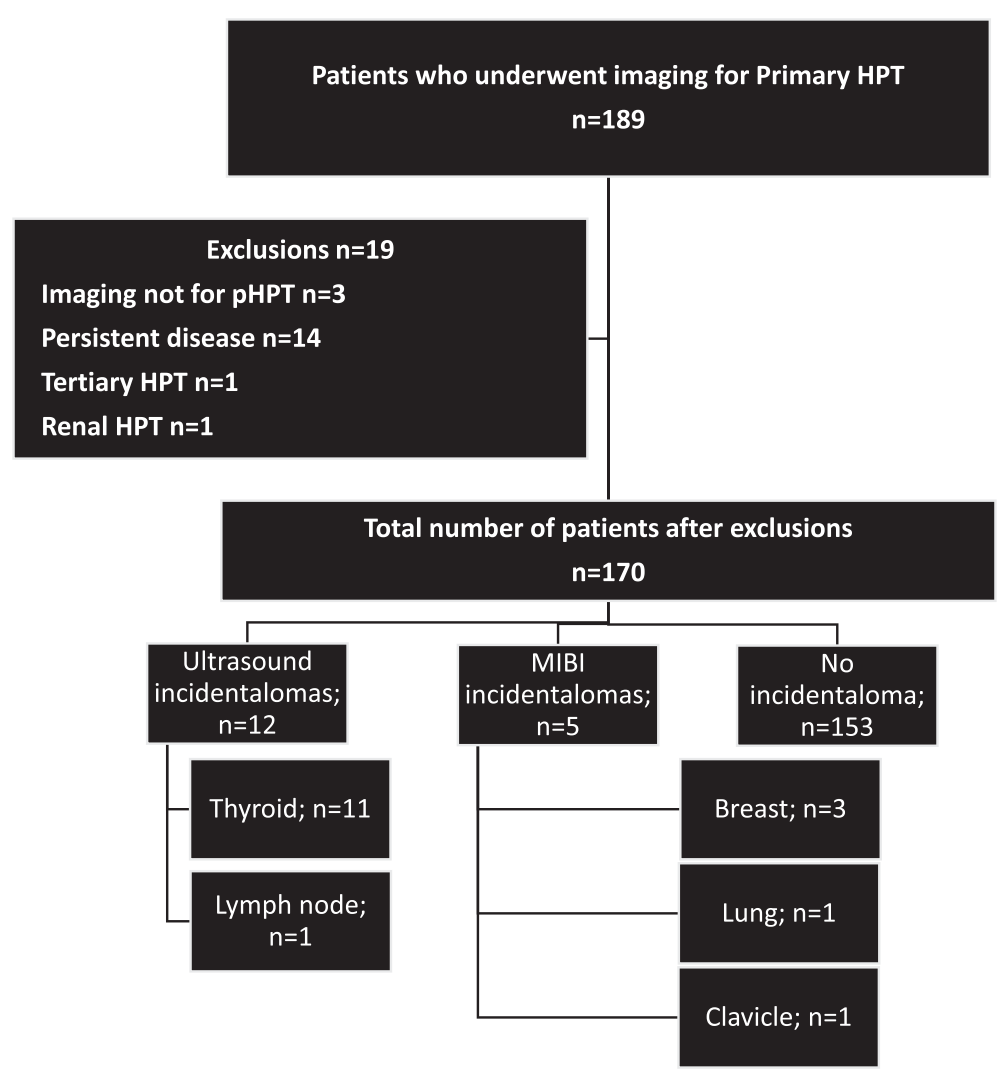

Fig. 1 Flow chart depicting the flow of patients in this study. Out of 189 patients, 19 were excluded as they did not meet the inclusion criteria for the study. Out of the 170 patients included in the study, incidentalomas were detected on ultrasound $(n=12)$ or MIBI $(n=5)$ alone. Sites of the incidentalomas include the thyroid gland $(n=11)$, breast $(n=3)$, lymph node $(n=1)$, clavicle $(n=1)$ and lung $(n=1)$. There was no concordance between the imaging modalities for any incidental lesion identified

\section{Discussion}

Advancements in modern imaging and surgical techniques have enabled surgeons to adopt a minimally invasive approach in the treatment of many patients with pHPT $[3,9]$. The success of such surgical approaches is largely dependent on accurate pre-operative localization of the overactive parathyroid gland(s) $[7,10]$. One of the disadvantages of imaging is the detection of incidental lesions elsewhere in the body. Such lesions may require further investigation and treatment, potentially predisposing them to increased morbidity and delaying treatment of the primary condition for which imaging was requested. In the setting of parathyroid gland imaging for adenoma localisation, there is a gap identified in the literature on the incidence and risks of incidentalomas, nature of such lesions, their investigation and management.

The $10 \%$ incidentaloma rate reported in our study is likely to be an underestimate. The vast majority of reporting was done by experienced consultant radiologists who have a special interest in parathyroid imaging. Thyroid nodules are commonly detected during ultrasound; however, only those that had equivocal or suspicious findings on imaging were highlighted by the radiologist and investigated further. Similarly, for MIBI

Table 1 Histology results of surgically excised thyroid tissue

\begin{tabular}{lc}
\hline Histology & Number of patients \\
\hline Florid Hashimoto's thyroiditis & 1 \\
Moderate thyroiditis & 1 \\
Multinodular goitre & 1 \\
Colloid goitre with incidental 1.5-mm & 1 \\
papillary microcancer & 1 \\
Benign appearance of thyroid tissue & 1 \\
\hline
\end{tabular}


reports, uptakes within physiological limits at other sites were not considered to be 'incidentalomas'. Despite the careful selection of 'incidentalomas' in this study, the results have demonstrated that there was no pathology of major clinical significance identified on further assessment. Whilst the cohort size is small, the benign nature of the incidentalomas detected in this study may help reassure both patients and clinicians that most of these lesions do not tend to be of clinical concern.

Ultrasound for parathyroid localisation has led to the detection of concomitant thyroid pathology. The incidence, nature and suggestions for management of the incidentally detected thyroid nodule during parathyroid imaging have been well documented in the literature $[5,8,11,12]$. However, there has been no study to our knowledge that examines the incidence, nature and management of extra-cervical incidentalomas identified during $\mathrm{PHPT}$ imaging.

\section{Thyroid incidentalomas}

Ogawa et al. [11] have highlighted the high prevalence of thyroid disease in patients with hyperparathyroidism; $10.6 \%$ of their patients had malignant thyroid tumours detected incidentally on ultrasound. A prospective cohort study by Adler et al. in 2010 [5] investigated the presence of thyroid pathology amongst 310 patients undergoing ultrasound for PHPT. Of the study population, $29 \%$ had an incidental thyroid lesion identified at the time of ultrasound. The study demonstrated that approximately $2 \%$ of all patients with pHPT undergoing an ultrasound had a thyroid malignancy.

In our study, only $6.5 \%$ had a thyroid nodule that merited further imaging or intervention. Only one patient had an incidental papillary microcancer on histology within a colloid nodule detected on an ultrasound scan; this is considered insignificant.

\section{Breast incidentalomas on nuclear imaging}

None of our three patients who had investigations for increased tracer activity in the breast had a clinically significant pathology identified. There have been reports of incidentally detected breast malignancies identified on imaging. For example, a study of suspicious breast findings in 902 women undergoing PET or CT scans identified 5 patients with a breast malignancy [13]. There are also reports that describe the detection of occult breast cancers in patients undergoing imaging with Tc99m MIBI [14-16].

\section{Other incidental lesions}

Pulmonary nodules are incidental lesions that are frequently identified on imaging for other clinical indications. The subsequent management and follow-up of these lesions is variable and largely dependent on the nodule size, imaging modality and associated clinical features [17-19]. $\mathrm{Wu}$ et al. [20] suggest that small pulmonary nodules in patients less than 50 years old with no history of malignancy are unlikely to be of clinical significance. The literature describes the use and high specificity rates of nuclear imaging, particularly Tc99m MIBI scans, in the evaluation and management of solitary pulmonary nodules [21].

Our study identified the presence of a pulmonary nodule on the MIBI scan performed in one patient, necessitating further investigations.

Our case series identified one patient with increased bony uptake at the time of MIBI; this was localised to the clavicle. Qui et al. [22] have described the detection of vertebral metastases on a MIBI scan, in a patient with a rare parathyroid carcinoma. Zhao and Wang [23] have highlighted the relation between a high level of intact PTH and bone uptake of MIBI, concluding that this could reflect a stage of metabolic bone disease.

\section{Limitations}

The results of this study are limited by the retrospective nature of the study design, the variability in the management of detected incidentalomas and the size of the cohort. A much larger sample size has the potential to detect clinically significant incidental lesions on parathyroid imaging. A multicentre study over a longer period of time could yield more precise estimates of the detection rate of lesions of clinical significance. This would allow a comprehensive study of the management practices adopted by different institutions, analyse the outcomes of the utilised management strategies and assist in the development of an appropriate management algorithm for such incidentalomas.

\section{Conclusions}

The incidence of incidental lesions amongst patients undergoing localisation studies for pHPT was $10 \%$. The clinical significance of these lesions is low. Although larger studies are required to assess the true clinical impact of detection of these incidentalomas, the results of this study serve to provide initial data that addresses the knowledge gap regarding the incidence and nature of these incidental lesions.

\section{Competing interests}

The authors declare that they have no competing interests.

\section{Authors' contributions}

SPB was responsible for overseeing the design of the study, data collection, analysis and critically revising the manuscript. PP was responsible for designing the study, collecting and interpreting the data and drafting the manuscript. BJH provided the patient data relevant for the study and critically revised the

manuscript. CC provided the radiology reports on cervical ultrasounds carried out in the study period and critically revised the manuscript. EL provided the radiology reports on nuclear imaging of the parathyroid glands in the study period and critically revised the manuscript. All authors have read and approved the final manuscript. 


\section{Acknowledgements}

We thank Mr Ovie Edafe (University of Sheffield Medical School) for assisting with the SPSS software required for the statistical analysis of the data.

\section{Author details}

${ }^{1}$ Endocrine Surgery Unit, Department of General Surgery, Sheffield Teaching Hospitals NHS Foundation Trust, Sheffield, UK. ²Department of Radiology, Sheffield Teaching Hospitals NHS Foundation Trust, Sheffield, UK. ${ }^{3}$ Academic Unit of Surgical Oncology, Department of Oncology, School of Medicine and Biomedical Sciences, The University of Sheffield, Sheffield S10 2RX, UK.

Received: 20 February 2015 Accepted: 7 September 2015

Published online: 17 September 2015

\section{References}

1. Mackenzie-Feder J, Sirrs S, Anderson D, Sharif J, Khan A. Primary hyperparathyroidism: an overview. Int J Endocrinol. 2011;2011:8. Article ID 251410.

2. Wermers RA, Khosla S, Atkinson EJ, Achenbach SJ, Oberg AL, Grant III CSM, et al. Incidence of primary hyperparathyroidism in Rochester, Minnesota, 1993-2001: an update on the changing epidemiology of the disease. J Bone Miner Res. 2006;21:171-7.

3. Starker LF, Fonseca AL, Carling T, Udelsman R. Minimally invasive parathyroidectomy. Int J Endocrinol. 2011;2011:Article ID 206502.

4. Sukam A, Rehyan M, Aydin M, Yapar AF, Sert Y, Canpolat T, et al. Preoperative evaluation of hyperparathyroidism: the role of dual-phase parathyroid scintigraphy and ultrasound imaging. Ann Nucl Med. 2008;22:123-31.

5. Adler JT, Chen H, Schaefer S, Sippel RS. Does routine use of ultrasound result in additional thyroid procedures in patients with primary hyperparathyroidism? J Am Coll Surg. 2010;211:536-9.

6. Carling T, Udelsman R. Focused approach to parathyroidectomy. World J Surg. 2008;32(7):1512-7.

7. Grant CS, Thompson G, van Farley D, Heerden J. Primary hyperparathyroidism surgical management since the introduction of minimally invasive parathyroidectomy: Mayo Clinic experience. Arch Surg. 2005;140(5):472-9.

8. Kwon JH, Kim EK, Lee HS, Moon HJ, Kwak JY. Neck ultrasonography as preoperative localization of primary hyperparathyroidism with an additional role of detecting thyroid malignancy. Eur J Radiol. 2013;82(1):e17-21.

9. Rio PD, Vicente D, Maestroni U, Totaro A, Pattacini GM, Avital I, et al. A comparison of minimally invasive video-assisted parathyroidectomy and traditional parathyroidectomy for parathyroid adenoma. J Cancer Educ. 2013;4(6):458-63.

10. Rubello D, Kapse N, Grassetto G, Massaro A, Al-Nahhas A. Minimally invasive radio-guided surgery for primary hyperparathyroidism: from preoperative to intraoperative localization imaging. Ann Endocrinol (Paris). 2010;71(6):511-8.

11. Ogawa T, Kammori M, Tsuji E, Kanauchi H, Kurabayashi R, Terada K, et al. Preoperative evaluation of thyroid pathology in patients with primary hyperparathyroidism. Thyroid. 2007;17(1):59-62.

12. Milas M, Mensah A, Alghoul M, Berber E, Stephen A, Siperstein A, et al. The impact of office neck ultrasonography on reducing unnecessary thyroid surgery in patients undergoing parathyroidectomy. Thyroid. 2005;15(9):1055-9.

13. Beatty JS, Williams HT, Gucwa AL, Hughes MP, Vasudeva VS, Aldridge BA, et al. The predictive value of incidental PET/CT findings suspicious for breast cancer in women with non-breast malignancies. Am J Surg. 2009;198(4):495-9.

14. Hod N, Mindlin L, Horne T. Detection of occult breast carcinoma during evaluation of a skeletal tumor by Tc-99m MIBI scintigraphy. Isr Med Assoc J. 2003;5(4):296-7.

15. Seker D, Seker G, Ozturk E, Bayar B, Kulacoglu H. An incidentally detected breast cancer on tc-99m MIBI cardiac scintigraphy. J Breast Cancer. 2012;15(2):252-4

16. García-Talavera P, Olmos R, Sainz-Esteban A, Ruiz MÁ, González ML, Gamazo C. Evaluation by SPECT-CT of an incidental finding of a thymoma and breast cancer in a myocardial perfusion SPECT with 99mTc-MIBI. Rev Esp Med Nucllmagen Mol. 2013;32(4):260-2.

17. Madani A, Spicer J, Alcindor T, David M, Vanhuyse M, Asselah J, et al. Clinical significance of incidental pulmonary nodules in esophageal cancer patients. J Gastrointest Surg. 2014;18(2):226-33.

18. Blagev DP, Lloyd JF, Conner K, Dickerson J, Adams D, Stevens SM, et al. Follow-up of incidental pulmonary nodules and the radiology report. J Am Coll Radiol. 2014;11(4):378-83.
19. Alpert JB, Fantauzzi JP, Melamud K, Greenwood H, Naidich DP, Ko JP. Clinical significance of lung nodules reported on abdominal $\subset$. Am J Roentgenol. 2012;198(4):793-9.

20. Wu CC, Cronin CG, Chu JT, Halpern EF, Sahani DV, Shepard JA, et al. Incidental pulmonary nodules detected on abdominal computed tomography. J Comput Assist Tomogr. 2012;36(6):641-5.

21. Minai OA, Raja S, Mehta AC, Sullivan EJ, Khan SU, Dasgupta A, et al. Role of Tc-99m MIBI in the evaluation of single pulmonary nodules: a preliminary report. Thorax. 2000;55(1):60-2.

22. Qiu ZL, Wu CG, Zhu RS, Xue YL, Luo QY. Unusual case of solitary functioning bone metastasis from a "parathyroid adenoma": imagiologic diagnosis and treatment with percutaneous vertebroplasty — case report and literature review. J Clin Endocrinol Metab. 2013;98(9):3555-61.

23. Zhao Y, Wang Q. Bone uptake of Tc-99m MIBI in patients with hyperparathyroidism. Ann Nucl Med. 2014;28(4):349-55

\section{Submit your next manuscript to BioMed Central and take full advantage of:}

- Convenient online submission

- Thorough peer review

- No space constraints or color figure charges

- Immediate publication on acceptance

- Inclusion in PubMed, CAS, Scopus and Google Scholar

- Research which is freely available for redistribution 